\title{
Assessment of the Homogeneity of Industrial Areas in the Region Using the Hoover Index
}

\author{
Anna Urasova*, and Dmitri Balandin \\ Ural Branch of the Russian Academy of Sciences, 620014 Ekaterinburg, Russia
}

\begin{abstract}
In modern science, particular importance is given to improving approaches to identifying homogeneous territories according to industry specifics, allowing to take into account the specifics and patterns of socioeconomic processes of similar groups of regions with the adoption of appropriate practical decisions. In the development of the theoretical and methodological foundations of the theory of regional economics in economic research, the tasks of overcoming the socio-economic differentiation of territories, improving the quality of the population, assessing the influence of factors on the level of wages are highlighted. Scientific work on the development of options for making managerial decisions when strategizing the development of Russia, taking into account the differentiation of the population of the regions by income level, and scenario studies are of particular relevance. The article examines the issue of assessing the homogeneity of industrial territories in the region using the Hoover index from the standpoint of the progressiveness of this direction of development of the theory and methodology of regional economics. To achieve this goal, the authors chose the methods of median and statistical analysis, which together made it possible to make calculations on the example of one of the industrial regions of the Russian Federation - the Perm Territory. The Hoover index was chosen as the assessment tool. Calculations have shown a directly proportional relationship between the population and the level of income of the population of the territories of the region, the larger the territory and the higher the level of industrial development, the higher the income of the richest residents; asymmetry in favor of the most industrially developed territories of the region, relative uniformity of incomes of the richest residents in other territories.
\end{abstract}

\section{Introduction}

Trends in the modern development of the national economy indicate the growing role of regions in ensuring the balanced economic development of the Russian Federation in the long term. The importance of the branches of material production as a driver of economic growth predetermines the increased interest in regions with a high concentration of industrial enterprises [1], which form territorial centers of added value and high human capital at the municipal level [2]. It should be noted that in the scientific literature

* Corresponding author: annaalexandrowna@mail.ru 
significant attention is paid to the improvement of industrial policy, structural transformation of the regional economy [3], industrial typology of Russian regions [4], regulation of social processes in industrial territories [5].

In the development of the theoretical and methodological foundations of the theory of regional economics, researchers single out the tasks of overcoming the socio-economic differentiation of territories [6], improving the quality of the population [7], assessing the influence of factors on the level of wages [8]. Scientific work on the development of options for making management decisions when strategizing the development of Russia, taking into account the differentiation of the population of the regions by income level [9], scenario studies [10], are of particular relevance.

The demand in the theory of regional economics for the analytical interpretation of various indicators is predetermined by the fact that the bodies of statistical observation in their activities concentrate on the systematization of the collected information in the dynamics of the development of specific subjects of observation. At the same time, interconnections and interdependencies, trends and influencing factors remain, as a rule, without proper assessment. The introduction of indicative management tools into the practice of state, municipal and sectoral regulation meets modern challenges and allows us to determine not only the quantitative, but also the qualitative content of development processes. In this regard, a progressive direction in the development of the theory and methodology of the regional economy is the improvement of approaches to the allocation of homogeneous territories according to industry specifics, which make it possible to take into account the specifics and patterns of socio-economic processes of similar groups of regions with the adoption of appropriate practical decisions.

The use of assessment tools in this direction determines the task of identifying homogeneous groups of territories according to various differentiating components of various indicators of regional development. In this study, we have identified the task of analyzing the homogeneity of industrial territories in the region (using the example of the Perm Territory) based on the use of the Hoover index.

\section{Materials and Methods}

The collection of data was carried out using the Regional Database, which assumes data sampling with a multi-level rubricator of indicators. The rubricator has a hierarchical structure and consists of sections, headings and subheadings included in them, as well as indicators located at the lower level of the hierarchy.

Two methods of data sampling have been used:

1) using the formation of tables by selecting indicators from the rubricator (manual prototyping), which involves the formation of the layout of the output table by the researcher independently

2) with the help of automatic generation of the territory passport with all incoming indicators (automatic prototyping), assuming automatic generation of the layout of the output table

As a result, data were selected for 25 territories of the Perm Territory. To process the data, the methods of median and index analysis were chosen, which made it possible to assess the homogeneity of the industrial territories of the region using the Hoover index

The data can be used by municipal and regional authorities in the process of forming socio-economic policy. 


\section{Results and Discussion}

The Perm Territory is an industrially developed constituent entity of the Russian Federation, all the patterns of socio-economic development of which are formed by the demand for industrial products in the international and domestic markets. It can be noted that the economy of the absolute majority of territorial municipalities of the Perm Territory is based on the activities of city-forming industrial enterprises. In turn, the sustainability of these enterprises is largely determined by industry affiliation, qualifications and adaptive abilities of top management to modern economic conditions. The most successful of the latter tend to top local rankings in terms of income.

We set out to determine how much the industrial territories of the Perm Territory would have lived on the income of their richest resident.

To answer this question, the Hoover Index was calculated. This index has several meanings. In this case, we mean by this index the following:

The Hoover index shows how many days the richest citizen of the territory will be able to cover the costs of the local budget in the absence of third-party funding.

At the first stage of the calculations, the following indicators have been determined (Figure 1):

1. Average monthly income of the richest citizen of the territory in 2018, rubles,

2. Average monthly payments to all employees of enterprises and organizations, rubles.

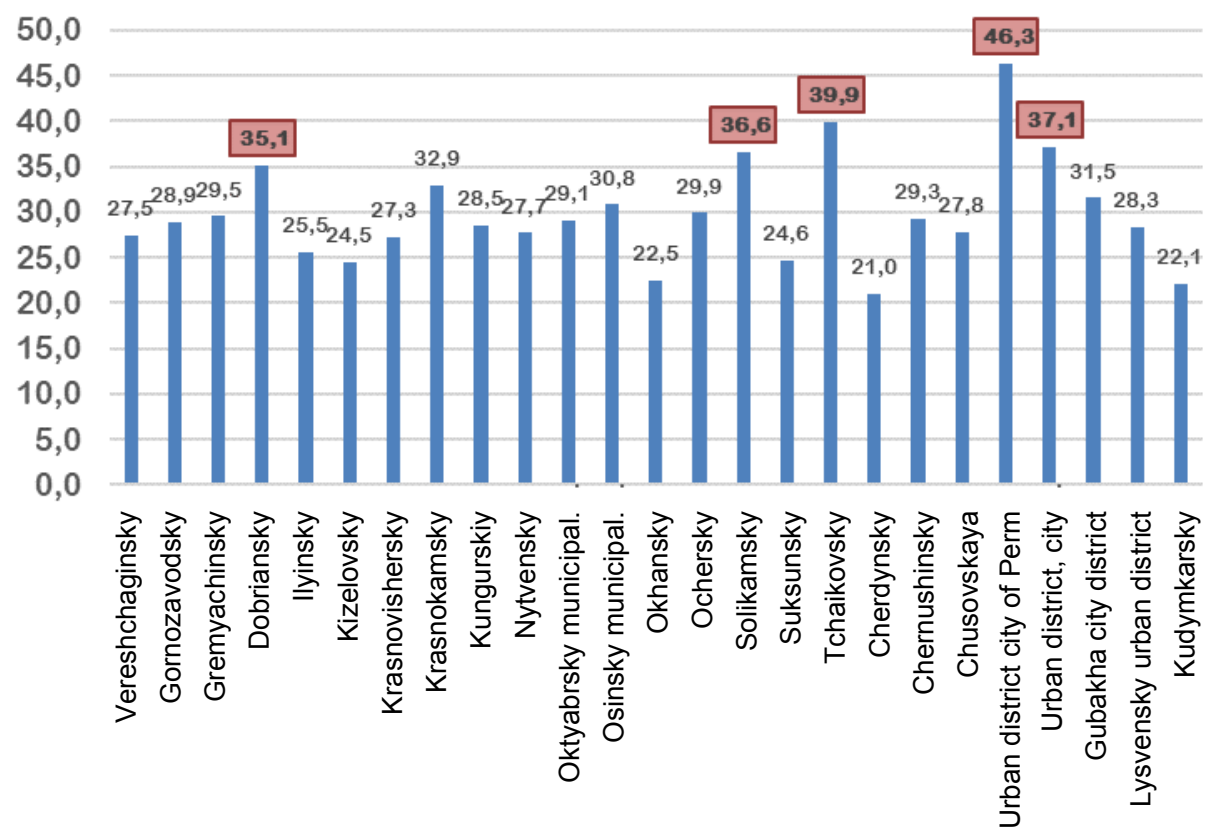

Fig. 1. Average monthly payments to all employees of enterprises and organizations, thousand rubles

At the second stage of calculations, the amount of daily income has been derived (Figure 2):

1. Daily income of the richest citizen of the territory in 2018, million rubles;

2. Daily payments to all employees of enterprises and organizations, rubles. 


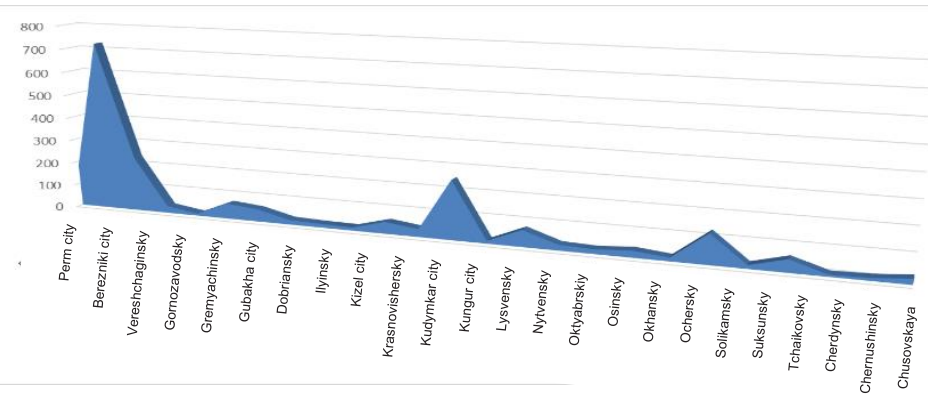

Fig. 2. Income of the richest citizen of the territory in 2018, rubles

At the third stage, the ratio of the indicators obtained at the second stage has been determined (the quotient of the indicators "Daily income of the richest citizen of the territory in 2018, rubles" and "Daily payments to all employees of enterprises and organizations (excluding small businesses), rubles". The number showing how many times the daily income of the richest citizen of the territory exceeds the daily payments to all employees of enterprises and organizations (excluding small businesses), is the Hoover Index

Figure 3 shows the values of the Hoover Index in descending order of their value in the industrial territories of the Perm Territory.

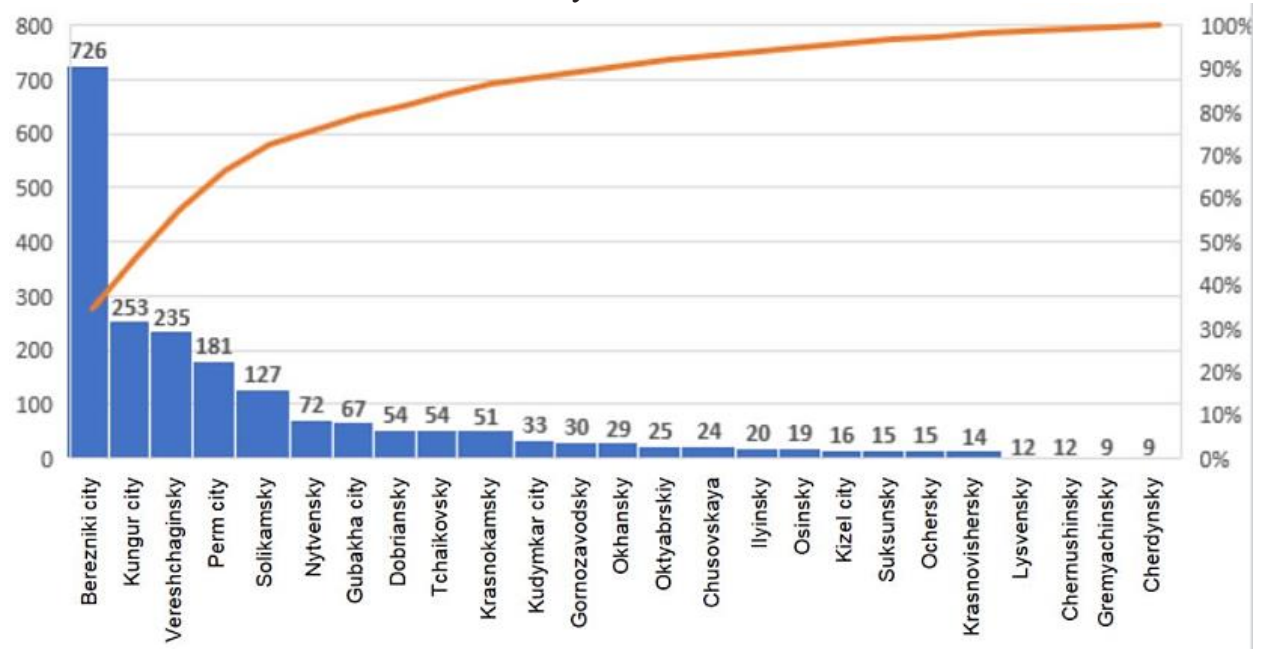

Fig. 3. Hoover index values for industrial territories of the Perm Territory, days

According to the results obtained, the richest man in the city of Berezniki could sponsor the budget of his territory for the longest time (726 days). In second place is the richest man in the city of Kungur (253 days). In third place in terms of the indicator under discussion is Vereshchagin urban district (235 days). Perm ranks fourth (181 days). The fifth place is taken by the Solikamsk urban district (127 days). The richest people of the Nytvensky, Dobriansky, Chaikovsky and Krasnokamsky urban districts, as well as the city of Gubakha, theoretically can finance an average of about two months. The Hoover index for other urban districts of the Perm Territory ranges from one week to a month.

Figure 4 shows the values of the Hoover Index on the map. 


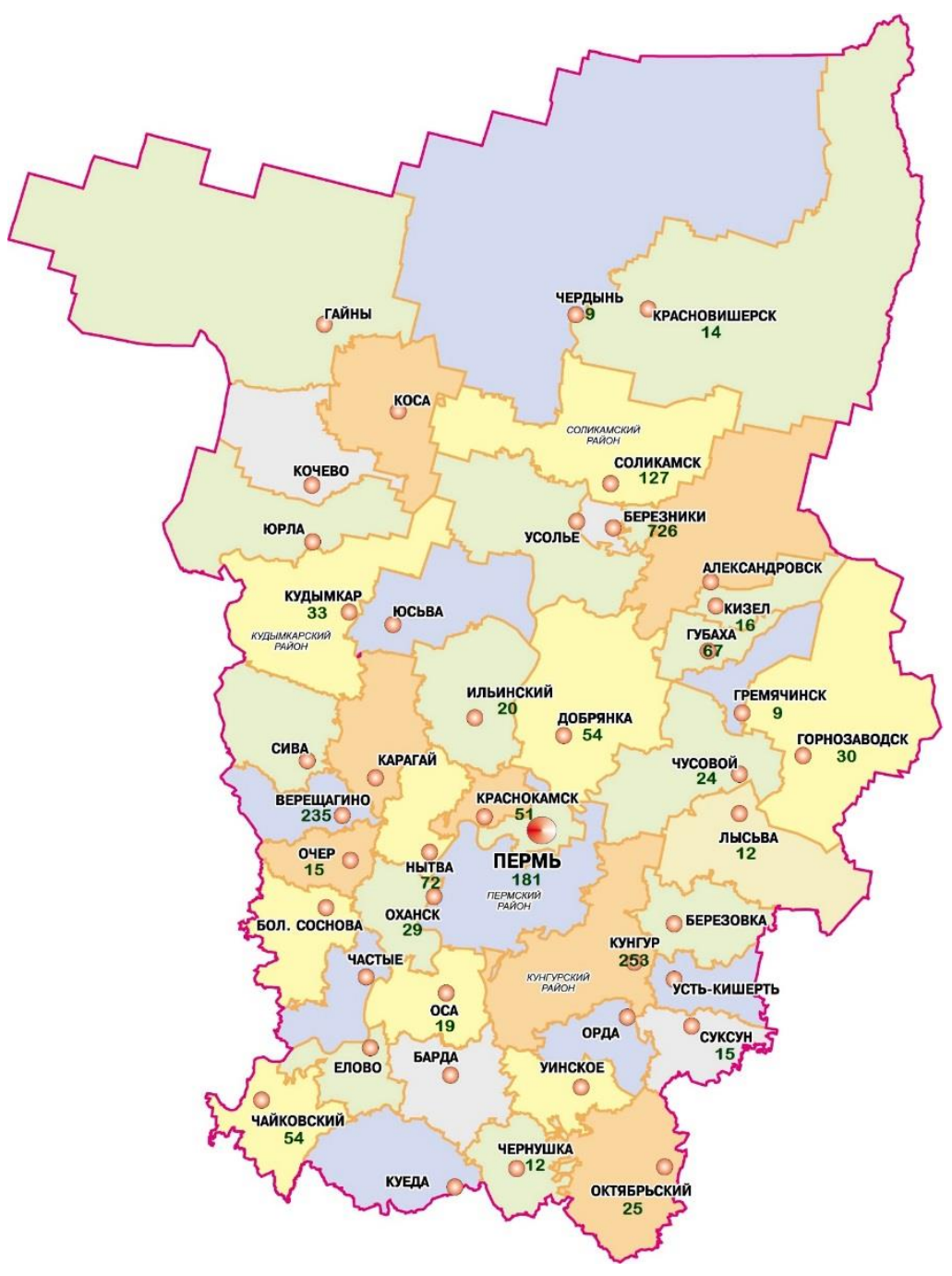

Fig. 4. Hoover index values for industrial territories of the Perm Territory, days

\section{Conclusions}

The assessment of the homogeneity of industrial territories of the Perm Territory using the Hoover index reflected the following trends:

1. The higher the population of the territory, the more unevenly the distribution of the income of the population; most of the territories have a similar level of unevenness $(10 \%)$;

2. level of wages in the industrial sector and related industries is in third - sixth positions;

3. the larger the territory and the higher the level of industrial development, the higher the incomes of the richest residents; asymmetry in favor of Perm and Berezniki, relative uniformity of income of the richest residents in other territories;

4. significant spread in the level of income between territories (from 21 to 46 thousand rubles). 


\section{Acknowledgements}

This work was financially supported by a grant from the President of the Russian Federation for State Support of Research by Young Russian Scientists-Candidates of Science (project MK-536.200.6).

\section{References}

1. T.V. Uskova, E.V. Lukin, A.E. Mel'nikov, E.G. Leonidova, Economic and Social Changes: Facts, Trends, Forecast, 10(4), 62 (2017)

2. I.D. Matskulyak, N.T. Sapozhnikova, G.P. Kharchilava, Upravlenets - The Manager, 10(4), 75 (2019)

3. E.V. Lukin, T.V. Uskova, Economic and Social Changes: Facts, Trends, Forecast, 11(6), 26 (2018)

4. Vercueil Julien, Economic and Social Changes: Facts, Trends, Forecast, 3(45), 108 (2016)

5. V. N. Bobkov, Yu. G. Odegov, A. P. Garnov, Economy of Region, 16(2), 522 (2020)

6. V. N. Bobkov, P. Herrmann, I. B. Kolmakov, E. V. Odintsova, Economy of Region, 14(4), 1061 (2018)

7. V.V. Lokosov, E.V. Ryumina, V.V. Ul'yanov, Economic and Social Changes: Facts, Trends, Forecast, 11(1), 32 (2018)

8. A.Y. Oshchepkov, Voprosy Ekonomiki, 11, 86 (2020)

9. T. I. Ladykova, V. L. Bersenyov, Economy of Region, 14(2), 380 (2018)

10. B.G. lyasov, E.A. Makarova, E. S. Zakieva, E.S. Gizdatullina, Economy of region, 15(2), 601 (2019) 